\title{
Back to the Future
}

\section{Dear Reader,}

Increasingly strict $\mathrm{CO}_{2}$ emissions legislation necessarily requires a focus on the electrification of the drive system. However, the sustainable success of electrified vehicles - in the sense of making up a significant proportion of the whole vehicle fleet - is a long time coming. It is all the more important, therefore, in the long transition phase to electric mobility, to consistently advance the development of vehicles with efficient internal combustion engines, with or without hybridisation.

Of course, when it comes to efficiency, the pure electric motor is certainly the best component in the chain, and it will be required wherever zero emissions need to be achieved locally. And the driving ranges of electric vehicles are perfectly respectable. Realistic ranges of 90 to $100 \mathrm{~km}$ from a fully charged battery are the rule, and with a rapid charging system this range can often be extended by a further 60 to $70 \mathrm{~km}$ within half an hour. At the same time, electric vehicles can significantly reduce local pollution caused by exhaust and noise emissions.

Now some may ask: what is this person talking about? We know all that already. Well, what is described above is not from today's news but is actually taken from an article published in ATZ 4 in 1956, with the promising title "The Importance of Electric Vehicles in Road Traffic”. It described a DKW delivery van with a $3.6 \mathrm{~kW}$ electric motor driving the front wheels and powered by "two batteries suspended at the side of the chassis generating a total output of $200 \mathrm{Ah}$ at a voltage of $80 \mathrm{~V}$ ". From the outside, the van looked no different from its gasolinepowered counterpart. In addition to discussing technical issues, the authors also considered the question of running costs, stating: "If the cost of renewing the battery is added to the running costs, the energy cost per kilometre for the electric car is 50 to $60 \%$ that of the gasoline-powered version.” They calculated "annual costs (without the driver) of 4400 Deutschmarks for a driving distance of 15,000 kilometres", which was 1800 Deutschmarks below those of a "gasoline car". By the way: in 1956, around 23,000 electrically powered industrial trucks and 7000 electric cars were in use in Germany.

Since then, technology has advanced in leaps and bounds. Batteries have become much smaller and lighter and driving ranges have (slightly) improved. Technically speaking, our engineers have prepared the ground well. It is now up to marketing experts and accountants to convince the customers.

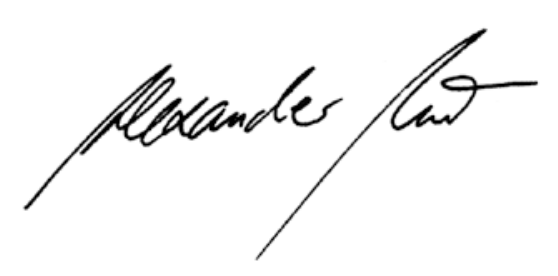

Dr. Alexander Heintzel

Editor in Chief

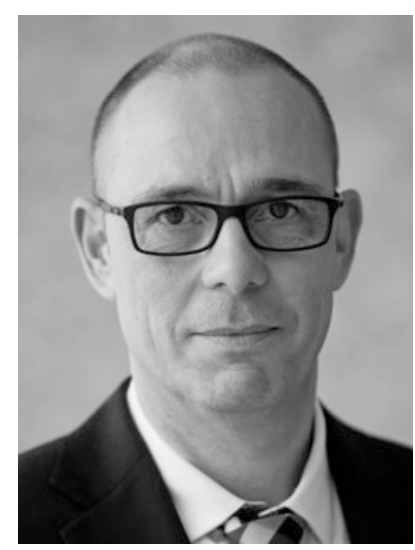

